\title{
El posconflicto como punto de encuentro para las transformaciones ocupacionales en Colombia
}

\author{
Pamela Talero Cabrejo ${ }^{1}$
}

Talero-Cabrejo, P. (2019). El posconflicto como punto de encuentro para las transformaciones ocupacionales en Colombia. Revista Ocupación Humana, 19(2), 3-7. $\underline{\text { https://doi.org/10.25214/25907816.862 }}$

Los estudios sobre conflictos armados alrededor del mundo evidencian que, en promedio, el $40 \%$ de los países que entran en procesos de posconflicto recaen durante la primera década desde el cese de hostilidades, siendo mayor el riesgo de reincidencia en los procesos iniciados a partir del año 2000 (Collier et al., 2008; Von Einsiedel et al., 2017). Esta alta probabilidad de reincidencia está asociada, en gran medida, al hecho de no abordar las causas del conflicto desde sus raíces. De esta manera, reconocer, estudiar y aprender de la pluralidad de narraciones que ocupan el territorio es fundamental en la construcción de la nación colombiana en posconflicto y en las transformaciones ocupacionales ${ }^{2}$ que se requieren para vivir en paz.

Así, entonces, este número está dedicado a reflexionar, caracterizar, contextualizar e imaginar la Terapia Ocupacional del posconflicto colombiano. No de un posconflicto visto únicamente

1 Terapeuta ocupacional. Doctora en Terapia Ocupacional. Profesora asistente adjunta, Thomas Jefferson University. Filadelfia, Pensilvania, Estados Unidos de América. pamela.talero@jefferson.edu. ID https://orcid.org/0000-0002-1057-9736

2 Se entienden como transformaciones ocupacionales los procesos multidireccionales y mutuos de cambio, influencia y adaptación de las formas y significados de hacer, ser, sentir, pensar y conocer que experimentan los sujetos en sus ocupaciones diarias, pero también aquellas personas que intervienen, estudian y atienden sus necesidades, desafiando los orígenes de las estructuras institucionales establecidas para la inclusión y la participación social (Duncan y Watson, 2004; Frank y Zemke, 2008; Sakellariou y Pollard, 2008; Laliberte et al., 2019). 
como la ausencia de conflicto (Caplan y Hoeffler, 2017), el cese de hostilidades o la fase posterior a la firma de los acuerdos de paz con las Fuerzas Armadas Revolucionarias de Colombia - Ejército del Pueblo (FARC-EP) el 24 de noviembre de 2016; más como un punto de encuentro. Este punto se plantea aquí, tal y como sería un área de refugio en caso de emergencia: una zona determinada para que las personas puedan evacuar, generalmente a campo abierto, en lo posible despejada, independiente y visible; o como un punto de encuentro familiar, un lugar neutral en situaciones de ruptura, donde los más pequeños puedan sentirse seguros (de la Torre Laso, 2006). En cualquiera de los dos símiles, el posconflicto es un lugar temporal, negociado, dinámico y frágil, en cuanto está distanciado de la zona de peligro pero no está exento de la confrontación ni desligado de la emergencia o la ruptura desde la cual emergió.

Por lo tanto, es necesario contextualizar el punto de encuentro. En esta ocasión, me permito hacerlo desde tres hechos precursores para este número: el XVI Congreso Colombiano de Terapia Ocupacional del 2016 y las celebraciones del Día del Terapeuta Ocupacional en Colombia del 2016 y el 2018. En primera instancia, el XVI Congreso Colombiano de Terapia Ocupacional, celebrado en marzo del 2016 en el marco de la conmemoración de los cincuenta años del inicio de la formación en Terapia Ocupacional en el país y con el lema cincuenta años ocupando contextos, transformando vidas, abrió interlocuciones sobre "nuestro compromiso social que significa la transformación de las vidas de las personas y los grupos sociales" (Rojas y Duarte, 2016, p.11). Las palabras de apertura del Congreso por parte de la entonces presidenta del Colegio Colombiano de Terapia Ocupacional (CCTO), Lida Pérez Acevedo, daban constancia del significado de ese momento histórico para la profesión y para el país, haciendo énfasis en "asumir los desafíos de un país que avanza, quizás no a una paz cercana y deseable, pero si a un país que está dispuesto a otro modo de organización, de convivencia y justicia social" (2016, p.15). Así, las memorias de dicho Congreso dan cuenta de las narraciones que se suscitaban desde la profesión, que en ese momento se venía preparando para asumir el posconflicto, como ilustra Aleida Fernández Moreno en su artículo de revisión "Conflicto armado en Colombia: aproximaciones desde la Revista Ocupación Humana, 1999 a 2019".

En noviembre de ese mismo año, la celebración del Día del Terapeuta Ocupacional en Colombia ocurrió en medio del tenso y sombrío panorama que el 2 de octubre de 2016 había generado. El plebiscito sobre los acuerdos de paz entre el Gobierno y las FARC-EP había sido rechazado ese día por el 50,2\% de los votantes, contra el 49,7\% que los apoyaban, y con una abstención de más del $60 \%$, mostrando las fuertes divisiones sociales, políticas e ideológicas a las que aún hoy nos enfrentamos. Sin embargo, fue ese panorama el segundo precursor desde donde el Colegio Colombiano de Terapia Ocupacional, con el lema Terapia Ocupacional: 50 años transformando conflictos en paz, persiguió el diálogo abierto sobre el papel de la profesión en el posconflicto. De esta manera, los artículos de reflexión de Andersson Julián Ospina Benavides, "Terapia Ocupacional en el tiempo histórico del Acuerdo de Paz: posibilidades y retos para ampliar nuestros campos de ac- 
ción", y de Solángel García Ruiz, "Algunas reflexiones bogotanas sobre el conflicto armado colombiano", dan cuenta de la necesidad de dimensionar el posconflicto como punto de encuentro para reconocernos en la pluralidad de narraciones y asumir responsabilidades sociales desde el estudio y el uso de la ocupación humana para la construcción de paz en contextos urbanos y rurales.

Finalmente, para la celebración del Día del Terapeuta Ocupacional del 2018, el Colegio Colombiano de Terapia Ocupacional y la Asociación Colombiana de Facultades de Terapia Ocupacional - ACOLFACTO realizaron una jornada académica y cultural alrededor del lema de la reconciliación a la acción, en la cual se evidenciaron los aciertos y desafíos de los procesos de reintegración a la vida civil de excombatientes de las FARC-EP, que se habían iniciado tras la firma del Acuerdo Final de Paz. Para ese entonces, aunque la ahora Fuerza Alternativa Revolucionaria del Común - FARC iniciaba su participación política legítima en la campaña electoral y postulaba candidatos al Congreso de la República, la implementación del Acuerdo enfrentaba ya varios retos. En esta jornada, las ponencias y discusiones daban cuenta de ellos a través de las experiencias que se venían desarrollando, augurando las transformaciones ocupacionales necesarias para los procesos de reconciliación y reintegración, algunas de las cuales se incluyen en este número, como: "Transformaciones ocupacionales en la implementación del Acuerdo de Paz en un espacio territorial de capacitación y reincorporación para excombatientes: un estudio de caso", por Nidya Alejandra Jiménez Moreno, Martha Liliana Tunjo López, Edwin Julián Espitia Bello, Judy Jassbleidy Pinzón Porras y Laura María Ramírez Arias; "Terapia Ocupacional en la ruralidad: una experiencia en La Macarena, Meta", por Claudia Patricia Rojas Castillo, Paula Alejandra Sánchez López, Lady Dayana Ramos Ramos y Danny Giseth Herrera Páez; "Aportes desde la universidad pública a la construcción de paz: prácticas formativas de Terapia Ocupacional y Fonoaudiología con un grupo de personas en proceso de reincorporación en Cali, Colombia", por Melania Satizabal Reyes y Andrea Aguilar Arias, y "Logros y retos de la atención integral de personas con discapacidad, víctimas del conflicto armado: aprendizajes de un proyecto de cooperación", por Eliana Ibeth Sepúlveda Zabala y Aleida Marcela Valbuena Pachón.

Así, las narraciones de este número ponen en evidencia el posconflicto como punto de encuentro que posibilita entender, desaprender y eliminar las violencias estructurales, también conocidas como violencia cultural, que han gestado y consolidado por más de cinco décadas el conflicto armado en nuestra sociedad (Galtung, 2016; Vélez y López, 2020). Sin embargo, tal y como los artículos lo identifican, aunque el proceso que atravesamos como país nos posibilita ocupar territorios y realidades antes inaccesibles, también nos reta a habilitarnos y capacitarnos para responder a las necesidades contextuales, a adaptarnos al cambio, a construir significados y a repensar los tiempos y lugares desde los cuales hilamos nuestro tejido social como nación, reconociendo las diferencias de nuestras fibras como ciudadanos, como lo muestra la entrevista a Ángela Cerón Lasprilla. 
Al considerar que la ocupación es un factor esencial para fomentar la salud, el bienestar, la calidad de vida, la experiencia de ser humano y la transformación social de las personas y las sociedades a las cuales pertenecen, la Terapia Ocupacional asume una responsabilidad ética no solo en el uso de la ocupación para lograr la transformación social, también en abogar para que las transformaciones sociales aborden la ocupación (Laliberte et al., 2019). Esto permite que las narraciones de los diferentes actores en este punto de encuentro tengan la oportunidad de convertirse en una práctica fundamental para generar democracia en un país que no solamente necesita contar lo sucedido y reconocer sus realidades excluyentes, desiguales y violentas (Vélez y López, 2020), sino que tienen el rol crítico de generar otros puntos de encuentro dentro del proceso de transformación nacional: zonas de refugio para contarnos como nación y como profesión.

\section{Referencias}

Caplan, R. y Hoeffler, A. (2017). Why peace endures: an analysis of post-conflict stabilization. European Journal of International Security, 2(2), 133-152. https:// EconPapers.repec.org/RePEc:csa:wpaper:2016-23

Collier, P., Hoeffler, A. y Söderbom, M. (2008). Post-conflict risks. Journal of Peace Research, 45(4), 461-478. https:// doi.org/10.1177/0022343308091356

de la Torre Laso, J. (2006). Los puntos de encuentro familiar: un enfoque actual de intervención en situaciones de ruptura familiar. Anuario de Psicología Jurídica, 16, 65-73.

Duncan, M. y Watson, R. (2004). Chapter 20. Transformation through occupation: towards a prototype. En R. Watson \& L. Swartz (Eds.). Transformation through Occupation (pp. 301-218). Whurr Publishers.

Frank, G. y Zemke, R. (2008). Occupational therapy foundations for political engagement and social transformation. En N. Pollard, D. Sakellariou y F. Kronenberg (Eds.). A political practice of occupational therapy (pp. 111-136). Elsevier.
Galtung, J. (2016). La violencia: cultural, estructural y directa. Cuadernos de estrategia, (183), 147-168.

Laliberte, D., Pollard, N., Craig, C., Kantartzis, S., Piškur, B., Algado Simó, S., Van Brugger, H. y Schiller, S. (2019). Contributing to social transformation through occupation: Experiences from a think tank. Journal of Occupational Science, 26(2), 316-322. https://doi.org/10.1080/144275 91.2018.1538898

Pérez Acevedo, L. (2016). Palabras de apertura. En C. Duarte (Ed.), Cincuenta años ocupando contextos, transformando vidas. Memorias del XVI Congreso Colombiano de Terapia Ocupacional (pp. 14-15). Colegio Colombiano de Terapia Ocupacional. https://doi.org/10.25214/25393766. congresoXVI

Rojas, C.P. y Duarte, C. (2016). Presentación. En C. Duarte (Ed.), Cincuenta años ocupando contextos, transformando vidas. Memorias del XVI Congreso Colombiano de Terapia Ocupacional (pp.11). Colegio Colombiano de Terapia Ocupacional. https://doi.org/10.25214/25393766. congresoXVI 
Sakellariou, D. y Pollard, N. Three sites of conflict and cooperation: class, gender and sexuality. En N. Pollard, D. Sakellariou y F. Kronenberg (Eds.). A political practice of occupational therapy (pp. 69-89). Elsevier.

Vélez, N. M. y López, F. (2020). Lectura, escritura y oralidad: la narración colectiva de Colombia en tiempos de posconflicto. Campos en Ciencias Sociales, 8(1). https://doi.org/10.15332/25006681/5721

Von Einsiedel, S., Bosetti, L., Cockayne, J., Salih, C. y Wan, W. (2017). Civil war trends and the changing nature of armed conflict. Occasional paper, 10. 